CLINICAL ISSUES

\title{
Heights of occupied patient beds: a possible risk factor for inpatient falls
}

\author{
Huey-Ming Tzeng PhD, RN \\ Associate Professor, The University of Michigan, School of Nursing, Division of Nursing Business and Health Systems, \\ Ann Arbor, MI, USA \\ Chang-Yi Yin MA \\ Professor, Department of History, Chinese Culture University, Taipei, Taiwan
}

Submitted for publication: 25 January 2007

Accepted for publication: 8 May 2007

\section{Correspondence:}

Huey-Ming Tzeng

Associate Professor

The University of Michigan

School of Nursing

Division of Nursing Business and Health

Systems

400 North Ingalls

Room 4156

Ann Arbor

MI 48109-0482

USA

Telephone: +1 7343580358

E-mail: tzeng_hueyming@yahoo.com, humi@umich.edu
TZENG H-M \& YIN C-Y (2008) Journal of Clinical Nursing 17, 1503-1509

Heights of occupied patient beds: a possible risk factor for inpatient falls

Aims. The aim of this study was to ascertain the average height of occupied patient beds in a general medical ward and to investigate the relationship between staff working-height for patient beds, time and whether the patient was on fall precaution.

Background. The height of occupied patient beds can be an overlooked contributor to inpatient falls. Better physical design of hospital equipment such as patient beds may reduce patient falls and injuries.

Methods. This study took place in an acute medical ward of a Michigan medical center. One researcher collected all the data and used the same metric for all the measurements. Univariate analyses were performed.

Results. The average staff working-height measurement taken at the weekend was significantly higher than that taken on weekdays. The average height of patient beds on fall precaution was significantly higher than of those not on fall precaution.

Conclusions. A higher patient/nurse ratio at weekends than on weekdays may result in fewer bedside nursing hours and nurses being less conscientious about keeping beds in the low position after treatments. In an effort to prevent high-fall-risk patients from falling, nurses may have consciously or unconsciously kept their beds in higher positions.

Relevance to clinical practice. If the patient bed can be manually or automatically adjusted, nurses must lower the height of the bed to the lowest position after completing treatments or tasks. This after-procedure activity should be enforced and monitored regularly as part of a hospital's patient fall prevention programme. Low beds should be used for patients at high risk of falling. Future research should investigate patients' and staff's views on hospital equipment to provide evidencebased information for policy-makers determining the design-regulation standard for hospital bedframes.

Key words: beds, falls, nurses, nursing, patient, safety 


\section{Background}

Safety refers to the condition of being protected from experiencing or causing injury, hurt or loss (MerriamWebster online dictionary 2007). The question therefore arises as to whether a better physical facility design would lead to better healthcare outcomes, such as fewer patient falls in acute care hospitals. A safety-driven, patient-centered facility design should be based on the evidence to promote quality care and patient safety. This should be a hospital design principle which takes account of both patient and staff points of view. Some research has suggested that the designregulation height and staff working-height for patient beds used in acute care wards may cause patient falls and contribute to the severity of fall-related injuries (Tzeng \& Yin 2006). Given that the height of occupied patient beds can be an overlooked contributor to inpatient falls, developing strategies or interventions to address the height of patient beds are imperative (Tzeng \& Yin 2007).

The Joint Commission Board of Commissioners approved National Patient Safety Goals for 2007 which emphasise the need to reduce the risk of patient harm resulting from falls and to implement a fall reduction programme that includes an evaluation of its effectiveness (The Joint Commission 2007). Although hospitals have devoted quality improvement and research efforts to prevent falls, patient falls still consistently comprise the largest single category of reported incidents in hospitals (The Joint Commission 2005). It may be that the height of patient beds is an overlooked cause of inpatient falls.

\section{Patient safety strategies and fall prevention in acute care settings}

Hospital can be a dangerous and erratic place for inpatients, including the unfamiliar physical environment (different from their home setting) and changes in their medical condition. Patient falls, defined as the rate at which patients fall during their hospital stay per 1000 patient days, are a nursingsensitive quality indicator in the delivery of inpatient services [American Nurses Association 2002]. Among the nursing quality indicators identified by American Nurses Association (2002), patient fall rates are perceived as the indicator that could be most improved through nurse-led interventions or safety strategies.

The Joint Commission (2005) categorised individual risk factors for falls as follows: (1) intrinsic risk factors (reduced vision, unsteady gait, musculoskeletal system deficit, mental status deficit, acute illness, chronic illness, etc.); and (2) extrinsic risk factors (medications, height of beds, bedside rails, lack of support equipment in bathtubs and toilets, condition of ground surface, poor illumination, inadequate assistive devices, etc.). As part of a continuing effort to promote patient safety and reduce falls, The Joint Commission (2005) suggested several environmental strategies related to bed height, mattresses and support devices, including: (1) the use of adjustable-height, high-low beds or fixed low-deckheight beds where applicable; (2) when feasible, keeping beds in their lowest position and providing mattresses firm enough to support safe bed transfers; and (3) providing a bed footboard to help patients as they transfer in and out of bed. Rather than using bed rails, JCAHO recommends that hospitals use adjustable beds that can be raised and lowered to enable patients to easily get in and out of beds and for staff to assist in this process.

Hignett and Masud (2006) took an ergonomic system perspective and applied Maslow's hierarchy of needs (e.g. fulfilling physiological and safety needs) when analysing inpatient falls. From a patient-centered perspective, the first hazard interaction is the bed (rails and height) in a patient ward. Previous studies in Western countries also concluded that $42-60 \%$ of inpatient falls were either bed-related or patients were found in their bed spaces after the falls (Masud 2003, Fonda et al. 2006). In summary, patient beds, as hospital equipment that patients spend most of their hospitalization time using, constitute an extrinsic risk factor for falls that hospital administrators might have overlooked.

\section{Difference in heights between home bedframes and hospital bed frames}

As indicated in Table 1, the height of a home bedframe may be as low as four inches (one inch = approximately two centimetres). However, the height of hospital bedframes in the low position ranges from 12-16 inches, and only two out of seven styles are 13 inches or lower in the low position (see the footnotes of Table 1 for the actual US bed manufacturer websites). According to British Standards BS4886 (The British Standards Institute 1988), an adjustable bedstead in the horizontal position is required to have at least two positions: 29.92-31.89 inches in the high position and 12.99-15.94 inches in the low position. The design-regulation heights of most hospital beds sold in the USA are comparable with the specifications of BS4886. Thus, hospital bedframes are still 8-12 inches higher than those of home bedframes. The difference in heights may contribute to inpatient falls related to getting in and out of bed, and to the severity of fall-related injuries.

Attempts have been made to establish how low a hospital bed should ideally be in the low position. Alexander et al. 
Table 1 Body and knee height of American males and females, and height specifications of home bed and hospital beds (see the footnotes for the actual US bed manufacturer websites)

\begin{tabular}{|c|c|c|c|}
\hline Variable & Male & Female & Data source \\
\hline Average age (in years) & $52 \cdot 7$ & $53 \cdot 6$ & \\
\hline Average body height* & 67.64 inches & 62.52 inches & \\
\hline Average knee height* & $21 \cdot 3$ inches & $19 \cdot 49$ inches & \\
\hline \multirow{2}{*}{$\begin{array}{l}\text { Home bed frame: height } \\
\text { from floor to top of deck** }\end{array}$} & \multicolumn{3}{|c|}{ Bed frame specification } \\
\hline & $\begin{array}{l}\text { Low profile bed fr } \\
4-5 \text { inches off th } \\
\text { Bold-on rails/fram }\end{array}$ & & \\
\hline Mattress** & $\begin{array}{l}\text { Mattress specificat } \\
\text { Mattress in firm st } \\
\text { inches (most of } \mathrm{tl} \\
\text { Regular box sprin } \\
\text { Low profile box st }\end{array}$ & & \\
\hline \multirow{9}{*}{$\begin{array}{l}\text { Electric high-low hospital } \\
\text { bed: height from floor to } \\
\text { top of deck in the low } \\
\text { position and in the high } \\
\text { position (low-high) }\end{array}$} & \multicolumn{3}{|c|}{ Company A: bed frame specification } \\
\hline & \multicolumn{3}{|c|}{ Style S (medical/surgical bed): $16-30$ inches } \\
\hline & \multicolumn{3}{|c|}{ Style G (medical/surgical bed): 14.5-29 inches } \\
\hline & \multicolumn{3}{|c|}{ Style E (medical/surgical bed): 13-30 inches } \\
\hline & \multicolumn{3}{|c|}{ Style L (medical/surgical bed): $12-28$ inches } \\
\hline & \multicolumn{3}{|c|}{ Company B: bed frame specification } \\
\hline & \multicolumn{3}{|c|}{ Style V (medical/surgical bed): $18-37$ inches } \\
\hline & \multicolumn{3}{|c|}{ Style C (medical/surgical bed): $15 \cdot 75-32 \cdot 5$ inches } \\
\hline & $\begin{array}{l}\text { Style T (ICU bed; } \\
\text { in the study ward } \\
\text { into the chair pos } \\
\text { to be passively m } \\
17 \cdot 5-36 \cdot 5 \text { inches }\end{array}$ & $\begin{array}{l}\text { oes } \\
\text { ent } \\
\text { on): }\end{array}$ & \\
\hline Mattress*** & \multicolumn{3}{|c|}{ Company A: mattress specification in height } \\
\hline & \multicolumn{3}{|c|}{ Style S: 7 inches } \\
\hline & \multicolumn{3}{|l|}{ Style X: 8.5 inches } \\
\hline & \multicolumn{3}{|l|}{ Style I: 6 inches } \\
\hline & \multicolumn{3}{|l|}{ Style P: 8 inches } \\
\hline & \multicolumn{3}{|c|}{ Style R: $6 \cdot 25$ inches } \\
\hline & \multicolumn{3}{|c|}{ Company B: mattress specification in height } \\
\hline & \multicolumn{3}{|c|}{ Style A: 8 inches } \\
\hline & \multicolumn{3}{|l|}{ Style P: 8 inches } \\
\hline & \multicolumn{3}{|l|}{ Style C: 7 inches } \\
\hline
\end{tabular}

*Body height refers to the distance from the floor to the top of the head in a standing person. Knee height refers the distance between the bottom of the heel pad and the top of the knee when both are flexed at $90^{\circ}$ (Roubenoff \& Wilson 1993).

$*$ Data are collected from the internet websites of the US based-companies for home bed and mattress retail (e.g. http://www.esleepshop.com/, http://www.us-mattress.com/, http://www.thebeddingsite.com/).

***The heights of selected electric hospital beds and mattresses are collected from the web sites of two US based companies (http://www. hill-rom.com/usa/, http://www.us-mattress.com/and http://med.stryker.com/).

(2000) found that all elders with a mean age of 82 years, in their study, could rise from sitting to standing from a seat at knee height using only their hands to assist them. This finding suggests that the height of the hospital bed from the floor to the top of the bed surface in the horizontal position should be adjustable to the patients' knee height (about 21 inches for males and 19 inches for females) (Roubenoff \& Wilson 1993). Using these two figures as references, the designregulation heights of hospital beds sold in the USA are indeed too high for physically frail patients to get in and out of bed safely and without fear of the distance from the floor to the bed edge (Table 1).

\section{Why do patients continue to fall?}

Depending on the styles of patient beds (e.g. the control panel for adjusting the overall height of the bedframe is not reachable by a patient who is lying on the bed), the patient 
might need to call someone to adjust the bed, if he or she is concerned about its height when moving out of, or back to, bed. This could lead to fear and insecurity (Tzeng \& Yin 2006, 2008). However, little research has systematically addressed the issue of the staff working-height, and designregulation height, for patient beds used in acute care settings, as possible causes for patient falls that result in injury.

\section{Purposes of this study}

This exploratory study aimed to illustrate the link between staff working-height for patient beds, time (weekday vs. weekend and time of day) and whether the patient was on fall precaution. The research questions were: (1) what is the average height of occupied patient beds in a general medical ward? and (2) what is the relationship between the staff working-height for patient beds, time, and whether patients were on fall precaution? This project was part of a patient safety improvement initiative in the study ward. The number of falls reported per 1000 patient days was 4.4 in August 2006.

\section{Method}

This study was conducted in a 32-bed, acute medical ward of a Michigan medical centre in October 2006. The bed-height measurements were taken only on occupied patient beds when nurses and physicians were not delivering bedside care at pre-determined time periods for data collection. After obtaining permission from the study ward's nursing manager, measurements were taken on two weekdays and one weekend day at three pre-determined time points on each day. As the study did not involve human or animal subjects, institutional review was waived.

Data were collected in one week. To ensure trustworthy measurement, one researcher collected all the data and used the same metric for measurements across all nine data collection time points. It was noted that one of this hospital's policies on fall prevention related to bed-height is that all beds should be left in the lowest position when actual patient care is not being provided.

\section{Data sources}

All the beds in the study ward are in the same style - an electric, high-low bed system, which is 23.5 inches high at its lowest position (including the heights of the bedframe [17.5 inches] and the mattress [six inches]). Only occupied beds, whether or not patients were lying on them, were measured from floor to the top of the middle part of the surface. If a nurse or physician was at the bedside (e.g. implementing procedures or administering medications or treatments) when the measurement was taken, this measurement was not included in the analyses. Any reminder notes of fall precaution indicated above the headboards were recorded.

Studied variables included bed-height in inches, weekday vs. weekend (weekday $=1$; weekend $=0$ ), time of data collection (morning: 9:30 AM to 10:30 $\mathrm{AM}=1$, afternoon: 1:30 PM to 2:30 PM $=2$, and evening: 6:30 PM to 7:30 $\mathrm{PM}=3$ ), and being on the fall precaution programme (yes $=1$, no $=0$ ).

\section{Analyses}

MICROSOFT OFFICE EXCEL was used for data entry and SPSS was used for analyses. Descriptive, independent $t$-tests and oneway ANOVA analyses were performed by using the staff working-height of patient beds as the dependent variable.

\section{Results}

Two hundred and eighty-eight measurements were included in the analysis. As shown in Table 2, the independent $t$-test demonstrated that the average staff working-height measurement taken at the weekend (mean $=26 \cdot 01$ inches) was significantly higher than that taken on weekdays (mean = $25 \cdot 32$ inches $)(t=-2.75, p=0.006)$. The average bedheight of patient beds that were on fall precaution (mean $=$ 26.34 inches) was significantly higher than those that were not on fall precaution (mean $=25.41$ inches $)(t=2.743$, $p=0 \cdot 007)$. One-way ANOva indicated that there was no statistically significant difference on the staff working-height measurements taken at different times $(F=2 \cdot 243$, $p=0 \cdot 108)$.

Using only weekday data, one-way ANOva indicated a statistically significant difference on the staff working-height measurements across different times (morning: mean $=$ $25 \cdot 10$ inches, $\mathrm{SD}=1 \cdot 17, n=63$; afternoon: mean $=25 \cdot 71$, $\mathrm{SD}=1 \cdot 91, \quad n=60$; evening: mean $=25 \cdot 13, \quad \mathrm{SD}=1 \cdot 29$, $n=54)(F=3 \cdot 159, p=0 \cdot 045)$. The average height during the weekday afternoon time points was the highest. No difference was found between the groups on fall precaution (mean $=25 \cdot 75$ inches, $\mathrm{SD}=2 \cdot 16, n=13$ ) and not on fall precaution $($ mean $=25 \cdot 28$ inches, $S D=1 \cdot 45, n=164)$ $(t=1 \cdot 076, p=0 \cdot 283)$.

When analysing only weekend data, no statistically significant difference was found in the staff working-height measurements taken between the three times (morning: mean $=25 \cdot 87$ inches, $\mathrm{SD}=2 \cdot 31, \quad n=31$; afternoon: mean $=26 \cdot 30, \mathrm{SD}=3 \cdot 44, n=28$; evening: mean $=25 \cdot 86$, 
Table 2. Relationship between staff working-height of patient bed (in inches), time and fall precaution programme

\begin{tabular}{|c|c|c|c|c|c|}
\hline Groups & Mean & SD & \multicolumn{2}{|c|}{ Frequency } & Per cent \\
\hline Bed height in inches (all subjects) & $25 \cdot 54$ & $1 \cdot 94$ & \multicolumn{2}{|c|}{ Range: $23-37 \cdot 20$} & \\
\hline \multicolumn{6}{|l|}{ Weekday vs. weekend } \\
\hline Weekday & $25 \cdot 32$ & $1 \cdot 51$ & & 177 & $67 \cdot 3 \%$ \\
\hline Weekend & $26 \cdot 01$ & $2 \cdot 55$ & & 86 & $32 \cdot 7 \%$ \\
\hline \multicolumn{6}{|c|}{ Independent $t$-test for equality of means (equal variances assumed): $t=-2 \cdot 75, p=0.006^{* *}$} \\
\hline \multicolumn{6}{|c|}{ Patient on the fall precaution programme } \\
\hline Yes & $26 \cdot 34$ & $2 \cdot 64$ & & 37 & $14 \cdot 1 \%$ \\
\hline No & $25 \cdot 41$ & $1 \cdot 77$ & & 226 & $85 \cdot 9 \%$ \\
\hline \multicolumn{6}{|c|}{ Independent $t$-test for equality of means (equal variances assumed): $t=2 \cdot 743, p=0 \cdot 007^{* *}$} \\
\hline \multicolumn{6}{|c|}{ Time of data collection } \\
\hline Morning (9:30 AM to 10:30 AM) & $25 \cdot 35$ & $1 \cdot 66$ & & 94 & $35 \cdot 7 \%$ \\
\hline Afternoon (1:30 PM to 2:30 PM) & $25 \cdot 90$ & $2 \cdot 50$ & & 88 & $33 \cdot 5 \%$ \\
\hline Evening (6:30 PM to 7:30 PM) & $25 \cdot 38$ & $1 \cdot 45$ & & 81 & $30 \cdot 8 \%$ \\
\hline \multicolumn{6}{|l|}{ One-way ANOVA: } \\
\hline & Sum of square & \multicolumn{3}{|c|}{ Degree of freedom } & Mean square \\
\hline Between groups & $16 \cdot 71$ & \multicolumn{3}{|c|}{2} & $8 \cdot 35$ \\
\hline Within groups & $968 \cdot 07$ & \multicolumn{3}{|c|}{260} & $3 \cdot 72$ \\
\hline Total & $984 \cdot 77$ & & 260 & & \\
\hline
\end{tabular}

$* * p<0.01$.

$F=2 \cdot 243, p=0 \cdot 108$.

$\mathrm{SD}=1 \cdot 65, n=27)(F=0 \cdot 266, p=0.767)$, and between the groups on fall precaution (mean $=26.66$ inches, $\mathrm{SD}=2 \cdot 85$, $n=24)$ and not on fall precaution (mean $=25 \cdot 75$ inches, $\mathrm{SD}=2 \cdot 41, n=62)(t=1 \cdot 493, p=0 \cdot 139)$.

\section{Discussion and conclusions}

\section{Staff working-heights, weekday vs. weekend and different shifts}

This study illustrates the relationship between the staff working-height for patient beds, times the measurements were taken, and whether the patient was on fall precaution. The findings of this study suggest that nurses have a tendency to keep patient beds higher at the weekend than on weekdays; the average bed-height measurement taken at the weekend was 26.01 inches and on weekdays 25.32 inches $(t=-2 \cdot 75$, $p=0.006)$. It is possible that for an acute inpatient ward (non-intensive care ward), fewer nurses are scheduled for work at weekends than during the week; reasons for this reduction in staff numbers include having fewer new admissions and discharges, scheduled procedures and treatments. Consequently the higher patient/nurse ratio at weekends may result in: (1) fewer bedside nursing hours and (2) nurses being less conscientious about keeping beds in the low position after treatments. One of the possible reasons why nurses tend to be less conscientious about keeping beds in the low position after treatments is having a feeling of being pressurised through lack of time.

In addition, there are more family visitors at weekends than during the week, which may contribute to nurses spending fewer bedside hours with patients. Further research is required to test whether these interpretations of the results can be verified.

Based on the analyses of the weekday data, the average staff working-height of patient beds in the afternoons was higher than that in the mornings and evenings. This may be because the height was left the same after 12:00 noon medication and treatment were administered. This finding suggests that further investigation may be needed to determine what kind of patient or nurse activities usually occur before and during this time period that require beds to be higher than in the morning and evening time periods.

\section{Bed height, fall precaution and use of restraint}

As we have observed in clinical practice, nurses have been repeatedly and thoroughly educated about the dangers of restraints, and the increased likelihood that a restrained patient will fall. Despite this, Vassallo et al. (2005) found that $84.5 \%$ of British healthcare professionals agreed that restraint use is justified to prevent fall-related injuries. Most agree that restraint use is at the discretion of healthcare professionals. Keeping patient beds in a higher position may 
be seen as a way to restrain high-fall-risk patients in bed by forcing them to call nurses when they need to leave the bed. Logically, however, if a patient falls from a higher bed, his or her fall-related injury is likely to be more severe than from a lower bed.

In this study, the average staff working-height of patient beds that were on fall precaution (mean $=26.34$ inches) was significantly higher than those that were not on fall precaution (mean $=25.41$ inches). This result may suggest that, in an effort to prevent high-fall-risk patients from falling, nursing staff consciously or unconsciously kept the beds in higher positions, possibly as a means of restraint which does not require physicians' order. Future research should address this possibility (e.g. by interviewing staff to ascertain their rationale for this practice).

\section{Practical implications}

Hospital quality improvement initiatives that focus on patient care have often been approached by building or maintaining a facility and instituting policies that provide care under safe conditions (National Academy of Sciences $2004 a, b)$. Applying this concept to practice with a focus on preventing bed-related inpatient falls, where the bed can be either manually or automatically adjusted, nurses and physicians must lower it to the lowest position after completing treatments or tasks. This after-procedure activity could help decrease patient fears when getting in and out of bed and prevent falls. In acute care settings, this action should be enforced and monitored regularly as part of a hospital's patient fall prevention programme.

Some hospitals are already using low beds (about six inches from the floor to the mattress surface) with patients who are at high risk for falls, particularly geriatric patients in areas such as transitional care units. In addition, nursing homes often purchase low-height beds for residents at high risk of falling; however, this practice has not yet been adopted in hospitals.

As indicated in Table 1, hospital beds which go into a 'chair' position are available, allowing patients to be passively moved into a sitting position. This type of bed has been used with almost all patients in the study hospital. However, during the data collection period on the study ward, the investigator only saw one nurse used the 'chair' function of the bed on one single patient. It seems that the 'chair' feature is seldom being used.

As indicated in Tables 1 and 2, the design-regulation height of hospital bedframes is much higher than the height of home bedframes. Nursing executives and hospital administrators need to keep in mind that, when purchasing new patient beds for acute care settings, the height of bedframes when in the low position should be specified as low as possible and be comparable to the height of home beds. As indicated in Roubenoff and Wilson's (1993) study, the average knee height for their female participants was 19.49 inches. To prevent fall-related injuries effectively, it is suggested that the patient bed (frame and mattress) should be no higher than $19 \cdot 5$ inches in the low position. This specification is important for building a patient-centered care environment which puts patient safety first; it is, however, only a first step, and more research is needed to determine the safest height for patient bedframes in the low position to guarantee patient safety.

\section{Future research}

To promote hospital patient safety (e.g. fall prevention), the design of hospital equipment (e.g. the height of beds) should be assessed for safety. Based on the results of this study, future research should investigate patients and staff's points of view about hospital equipment as related to patient safety. We also need to understand the relationship between the height of home beds and users' knee height, as users always make a choice of home beds based on their personal preferences, physical condition, and comfort levels (e.g. height of home bedframe and firmness of mattress). These future research efforts should estimate the safest height for patient bedframes to build a safe, patient-centered, home-like hospital care environment. The results of these efforts will provide evidence-based information to assist policy-makers to determine the practical design-regulation standard for the height of hospital bedframes.

\section{Source of support}

Not applicable.

\section{Contributions}

Study design: HMT, CYY; data collection and analysis: HMT; manuscript preparation: HMT.

\section{References}

Alexander NB, Galecki AT, Nyquist LV, Hofmeyer MR, Grunawalt JC, Grenier ML \& Medell JL (2000) Chair and bed rise performance in ADL-impaired congregate housing residents. Journal of the American Geriatrics Society 48, 526-533.

American Nurses Association (2002) Quality Indicators: Outcomes Measurement Using the ANA Safety and Quality Indicators. Available at: http://nursingworld.org/mods/archive/mod72/ceomfull.htm (accessed on 17 March 2007). 
Fonda D, Cook J, Sandler V \& Bailey M (2006) Sustained reduction in serious fall-related injuries in older people in hospital. The Medical Journal of Australia 184, 379-382.

Hignett S \& Masud T (2006) A review of environmental hazards associated with in-patient falls. Ergonomics 49, 605-616.

Masud T (2003) Audit of Falls in the Medical Directorate. Internal Report. Nottingham City Hospital, NHS Trust, Nottingham, UK. Merriam-Webster Online Dictionary (2007) Safety. Available at: http://www.m-w.com/dictionary/safety (accessed on 8 May 2007).

National Academy of Sciences (2004a) Executive Summary-Patient Safety: Achieving A New Standard for Care. Available at: http:// books.nap.edu/catalog/10863.html (accessed on 22 January 2007).

National Academy of Sciences (2004b) Executive Summary-Keeping Patients Safe: Transforming the Work Environment of Nurses. Available at: http://books.nap.edu/catalog/11151.html (accessed on 22 January 2007).

Roubenoff R \& Wilson PWF (1993) Advantage of knee height over height as an index of stature in expression of body composition in adults. The American Journal of Clinical Nutrition 57, 609-613.

The British Standards Institute (1988) Specification for Hospital Bedsteads. The British Standards Institute, London, UK.
The Joint Commission (2005) Defining the problem of falls. In: Reducing the Risk of Falls in Your Health Care Organization (Smith IJ ed). The Joint Commission, Oakbrook Terrace, IL, pp 13-27.

The Joint Commission (2007) National Patient Safety Goals-Facts about the 2007 National Patient Safety Goals. Available at: http:// www.jointcommission.org/PatientSafety/NationalPatientSafetyGoals/ 07_npsg_facts.htm (accessed on 22 January 2007).

Tzeng HM \&Yin CY (2006) The staff-working height and the designing-regulation height for patient beds as possible causes of patient falls. Nursing Economic 24, 323-327.

Tzeng HM \& Yin CY (2007) Height of hospital beds and inpatient falls: a threat to patient safety. Journal of Nursing Administration 37, (in press; December 2007).

Tzeng HM \& Yin CY (2008) Innovation in patient safety: a new task design in reducing patient falls. Journal of Nursing Care Quality 23, (in press; January 2008).

Vassallo M, Wilkinson C, Stockdale R, Malik N, Baker R \& Allen S (2005) Attitudes to restraint for the prevention of falls in hospital. Gerontology 51, 66-70. 